\title{
PERFIS DE VENTO E TURBULENCIA ATMOSFÉRICOS SIMULADOS EM TÚNEL DE VENTO
}

\author{
Daniel Schuch $^{1}$, Edson Marciotto ${ }^{2}$, Gilberto Fisch ${ }^{2}$, Ana Cristina Avelar ${ }^{2}$ \\ ${ }^{1}$ Instituto Tecnológico da Aeronáutica \\ ${ }^{2}$ Instituto de Aeronáutica e Espaço
}

\section{RESUMO}

O perfil de vento e a turbulência foram estudados a partir de medidas obtidas com um anemômetro de fio quente em ensaios de túnel de vento com um modelo de cavidade rasa. Foi determinada a Escala Integral Euleriana e os resultados sugerem que a estrutura da turbulência é controlada, principalmente, pela entrada de energia a sotavento da cavidade.

\section{ABSTRACT}

The wind and turbulence profiles were obtained from hot-wire anemometry inside a wind tunnel with a cavity model. It was determined the Eulerian Integral Scale and the results suggests that the turbulence is mainly controlled by the energy of the free flow in the leeward of gap.

\section{INTRODUÇÃO}

O escoamento atmosférico pode ser simulado, por exemplo, com o uso de modelos numéricos, sendo uma prática comum em centros de meteorologia e que vem sendo extensivamente usada tanto como ferramenta de pesquisa como procedimento operacional. Porém, simulações numéricas não são o único tipo de ferramenta disponível, sobretudo na área de pesquisa. Uma série de técnicas onde se utilizam combinações de diferentes modelos físicos como maquetes que representam determinadas geometria, em conjunto com sensores e sistemas de aquisição de dados com alta resolução temporal e espacial também podem ser usadas para o mesmo fim.

O presente trabalho apresenta resultados ensaiados em túnel de vento com uma maquete estática de cavidade representando a geometria de regiões de pequenas clareiras em florestas (RAUPACH et al., 1996) ou de "canyons" urbanos (KASTNER-KLEIN et al., 2001).

\section{METODOLOGIA}

Os resultados foram obtidos a partir de ensaios no Túnel de Vento (TA-3) localizado no Instituto de Aeronáutica e Espaço (IAE), São José dos Campos, Brasil.

O modelo físico utilizado consiste em uma cavidade de altura fixa ( $h=43 \mathrm{~mm}$ ) e largura $L=6 h$. Foi obtido o perfil vertical de velocidade nas alturas normalizadas $z / h=0,1 ; 0,3$; 0,$5 ; 0,7 ; 0,9 ; 1,0 ; 1,1 ; 1,5 ; 2,0$ e 2,5 em relação à depressão do modelo (como ilustrado na Figura 1), sendo que o eixo $x$ (longitudinal) está alinhado com a velocidade do vento médio e a origem está no início da cavidade (entrada da cavidade). As medidas foram realizadas considerando-se três velocidades do fluxo livre de 2,5 e $10 \mathrm{~m} / \mathrm{s}$. 


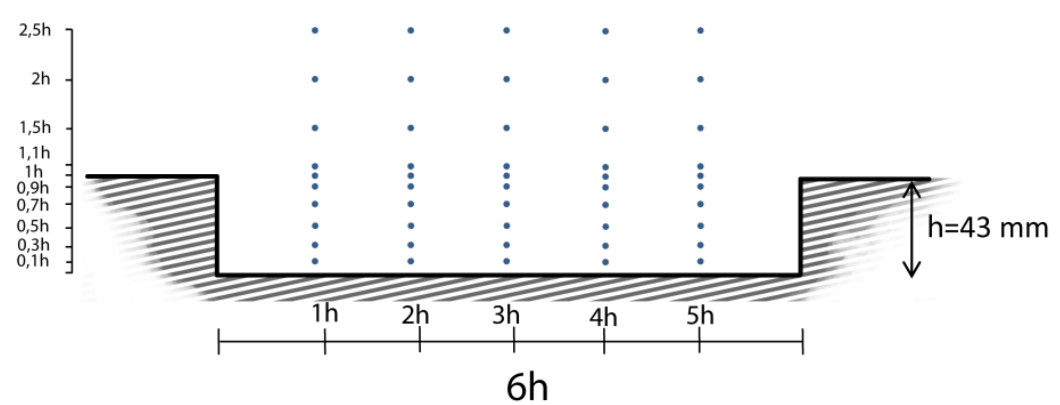

Figura 1 - Representação esquemática mostrando os pontos onde foram realizadas medidas no interior da cavidade

Salienta-se que a velocidade medida pelo anemômetro de fio quente não representa puramente a velocidade longitudinal do escoamento, mas sim uma velocidade efetiva ( $\left.U_{\text {eff }}\right)$, seguindo a seguinte relação:

$$
U_{e f f}^{2}=u^{2}+w^{2}
$$

A partir do espectro de energia turbulenta foi determinada a Escala de comprimento Integral Euleriana (FOKEN, 2006).

\section{RESULTADOS}

A seguir, são apresentados o perfil de velocidade, intensidade da turbulência ensaiados em túnel de vento e Escala Integral Euleriana calculada para cada posição. São apresentados os valores médios entre os experimentos com velocidade de 2,5 e $10 \mathrm{~m} / \mathrm{s}$.

Na Figura $2 a$, é apresentado o perfil do vento médio para cada posição no interior da cavidade. Em alturas acima de h, ele apresenta-se na forma logarítmica, com exceção da posição próxima à saída da cavidade $(\mathrm{x} / \mathrm{h}=5)$. Esse efeito está relacionado primeiramente com a recirculação no interior da cavidade e também à reentrada de fluxo que alimenta essa recirculação. No interior da cavidade é possível notar um mínimo local de velocidade em $\mathrm{z} / \mathrm{h}=0,3 \mathrm{em}$ algumas posições.
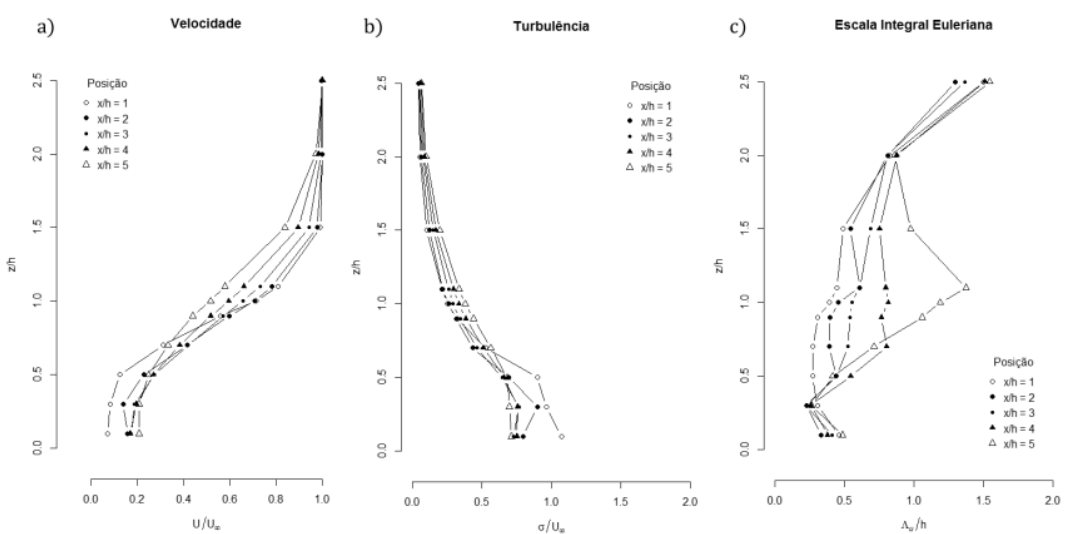

Figura 2 - Perfil de velocidade (a), turbulência (b) e escala integral euleriana (c)

O perfil de turbulência (Figura $2 b$ ) apresenta uma curva com máximos próximos à altura de $\mathrm{z} / \mathrm{h}=0,3$, que é a altura onde ocorre o máximo de cisalhamento do vento. Tanto o perfil de 
turbulência como o de velocidade do vento tende a se distribuir melhor verticalmente, na medida em que a posição se afasta da entrada da cavidade.

A escala integral euleriana (Figura $2 c$ ) apresentou seu valor máximo na posição $\mathrm{x} / \mathrm{h}=5 \mathrm{e}$ altura de $\mathrm{z} / \mathrm{h}=1,1$. O valor calculado representa o comprimento característico dos movimentos que transferem energia do escoamento livre para a recirculação no interior da cavidade, e subsequentemente, de energia mecânica para a geração de turbulência.

\section{CONCLUSÃO}

Os perfis de velocidade e turbulência ensaiados no túnel de vento são consistentes com o previsto pela teoria e coerentes com observações em regiões de clareiras e canyons urbanos.

Foi determinada a escala horizontal de entrada de energia (grandes turbilhões) induzindo pela geometria de cavidade. A cavidade influenciou significativamente o comportamento do fluxo acima, mas apenas próximo a sua saída. No interior da cavidade, a região de entrada tende a ser uma região de estagnação.

Agradecimentos: Os autores agradecem ao apoio financeiro do CNPq através de Bolsa DTI (380026/2013-9) para o autor D. S. e bolsa PQ (303720/2010-7) para o autor G. F. O autor E.R.M. agradece à FAPESP (Proc. 2010/16510-0) e ao CNPq (Proc. Universal 471143/2011-1) pelo suporte financeiro.

\section{REFERÊNCIAS:}

FOKEN, T. Micrometeorology. 1.ed. Heidelberg, Berlin: Springer-Verlag, 2006. 306 p.

KASTNER-KLEIN, P., FEDOROVICH, E., ROTACH, M. W.. A wind tunnel study of organized and turbulent air motions in urban street canyons. Journal of Wind Engineering and Industrial Aerodynamics, v. 89, p. 849-861, 2001.

RAUPACH, M. R.; FINNIGAN, J. J.; BRUNET, Y.. Coherent eddies and turbulence in vegetation canopies: the mixing-layer analogy. Boundary-Layer Meteorology, v. 78, p. 371-382, 1996.

RODRIGO, J. S.; BEECK, J. V.; DEZSÖ-WEIDINGER, G. Wind tunnel simulation of the wind conditions inside bidimensional forest clear-cuts: application to wind turbine sitting. Journal of Wind Engineering \& Industrial Aerodynamics, v 95, n. 7, p. 609-634, 2007. 